International Journal of Linguistics, Literature and Translation

ISSN: 2617-0299 (Online); ISSN: 2708-0099 (Print)

DOI: $10.32996 / \mathrm{ijllt}$

Journal Homepage: www.al-kindipublisher.com/index.php/ijllt

\title{
The Study of the Coherence of English Learning Strategies Used for Understanding Science Modules by Science Students in the EFL Reading Process
}

\author{
Kritchada Ruangnoi ${ }^{1} 8 \mathbb{( D )}$, Jarinya Srimanee ${ }^{2} 8(\mathbb{D})$ and Mohamad Jafre Bin Zainol Abidin ${ }^{3} 8(\mathbb{D}$ \\ ${ }^{1}$ Ph.D. Students, University of Sains Malaysia; Director of Excellent Academic School, Hat - Yai, Songkhla, South of Thailand \\ ${ }^{2}$ Lecturer of English, College of Industrial Technology and Management, Rajamangala University of Technology Srivijaya \\ ${ }^{3}$ Lecturer of English, College of Industrial Technology and Management, Rajamangala University of Technology Srivijaya; \\ Assoc. Prof. Ph.D., School of Educational Studies, University of Sains Malaysia
}

$\triangle$ Corresponding Author: Kritchada Ruangnoi, E-mail: kritchada@hotmail.com

ARTICLE INFORMATION ABSTRACT

Received: February 15, 2021

Accepted: March 05, 2021

Volume: 4

Issue: 3

DOI: 10.32996/ijlt.2021.4.3.20

\section{KEYWORDS}

Reading Strategies, EFL, Scientific Reading, Reading comprehension
This study investigates the effectiveness of reading strategies employed by Thai EFL lower secondary students of the scientific ability program at one private and two government secondary schools in Thailand's southern province. The study integrated cognitive, metacognitive, determination, social, and memory strategies into the reading treatment. The results are expected to enhance the student's regulation in applying the reading strategies instruction techniques. The study's participants were thirty Thai EFL students from Grade 7 in a government secondary school in southern Thailand. The data were analyzed and interpreted quantitatively and qualitatively. The training program consisted of five reading strategies, eight scientific reading modules, and a variety of enriching and engaging activities. Therefore, the thematic analysis of the interview data revealed overall satisfaction and enhanced students and teachers' positive attitudes towards Science in English and the benefits of using reading for developing a Science curriculum.

\section{Introduction}

Looking at the development of foreign language ( $F L)$, studying has mainly been extracted from hypotheses and insights within the First Language (L1) reading studies. Maximum FL researchers also undertake and regulate analyzing thoughts and expert perspectives in L1 reading technology, often performed in English language contexts (Stevenson, 2010). There are unique elements of L2 studying experiments that cannot be shared with L1 analyzing assessments, inclusive of linguistic information, processing competencies, individual variations, language surroundings, sociocultural background, and institutional expectations (Bernhardt, 2003; Grabe, 2004; Koda, 2007).

The students must address, undertake, and adapt reading within everyday educational existence. In step with Wallace (2003), students will interact with their attitudes, motivation, past historical knowledge in science, or even personal hobbies while trying to comprehend the texts. College students who regularly have problems studying to decode and understand words and meanings will most-likely face difficulties in analyzing and expertise; they are now not uncovered to more outstanding challenging textual content and often locate the reading revel in difficult and finally surrender. As a result, those college students are not exposed sufficiently to possibilities to expand linguistic skills and get to know techniques to come to be gifted readers (Lens, 2010).

This research mainly focused on reading teaching science strategies in English for the government secondary students south of Thailand. It would beautify students' high-quality attitudes in the direction of Science in English reading and enhance the English instructors' cognizance of the benefits of studying as assets for developing Science and English curriculum. Sooner or later, they will shed light on EFL reading techniques coaching mainly for English educators and administrative officers to not forget

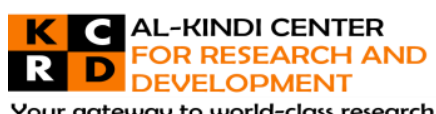

Your gateway to world-class research

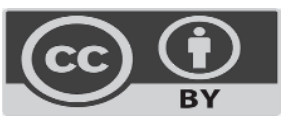

Published by Al-Kindi Center for Research and Development. Copyright (c) the author(s). This open access article is distributed under a Creative Commons Attribution (CC-BY) 4.0 license 
teaching science congruently with English. It is far hoped that future studies may also employ all styles of studying strategies guidance information to broaden a few robust studies gadgets for EFL students.

The coaching and learning of English in Thailand commenced within the late 19th-century with individual assignment schools' status quo teaching English to commoners 'beyond the palace'. With English included within the curriculum, Western-fashion primary faculties have been stepped by step set up across the kingdom, replacing the traditional Buddhist monastery schooling (Ministry of schooling, 2008). In the 20th century, Thais had been encouraged to study English because of the global language of technological know-how, generation, aviation, commercial enterprise, and international relations (Kitjaroonchai, 2012). Over the years, the English language has carried out an especially high repute in Thai society, and its role is taken into consideration more massively than that of every other foreign language (Darasawang, 2007), and is significantly more essential in that it is far a pressing problem (Darasawang \& Watson, 2012).

Science has become a compulsory topic for Thai students in every grade, from the primary level to the upper-secondary level, and the time allocated for science instruction is 80 lessons per year starting from the first-grade level and at all primary levels (IPST, 2002). This reform challenged teachers to learn how to teach science for young children, especially those involving abstract concepts. Many students have difficulties in science because they receive information without understanding it. They begin reading science assignments without thinking about the subject and their counterparts and interact with the text to construct meaning. They make predictions, ask questions, generate questions, and vigorously seek answers. Mokhtari, Kouider, Reichard and Carla (2003) posited that to be successful in reading science text materials, one must be aware of what they are reading; they seem to know why they are reading, and they have asserted tentative plans or strategies for handling potential problems and for monitoring their comprehension of textual information.

In keeping with Wiriyachitra (2001), Thais have high proficiency in era however cannot make plenty of development in terms of science and era due to their beneath-common English competency in contrast with many countries in Asia (e.g. Malaysia, Philippines, and Singapore). Wiriyachitra concluded that English language teaching in Thailand has no longer ready Thais for growing surroundings, resulting in Thais stagnating in the back of an international business world, schooling, technology, and technology.

This finally ends up inside the failure of growing readers to know the vital meaning of texts through interactive analyzing processing. Beneath this sort of training, students will not have the threat to watch their very own analyzing method or to clear up their very own analyzing problems. Typically, college students do not appear to be encouraged to observe what they want to understand and what they need no longer. Furnished that they cannot become aware of the supply in their troubles, they may have trouble regulating their reading techniques autonomously. The observations above may also bring about the realization that the coaching of English-studying in Thailand remains influenced by means of passive and backside-up fashions of the studying process, which had been common in the mid-Nineteen Seventies (Hood, Solomon \& Burns, 1996).

The research intends to study the coherence of various English learning strategies used to understand Science modules. Furthermore, the study also examines the reading strategies employed by Thai EFL students during their scientific reading, how they applied reading strategies to shed light on the difficulties and challenges encountered while reading. Furthermore, the researcher also attested some ways to enhance their scientific reading proficiency and reading strategies instructions on students' reading comprehension.

\section{Research Methodology}

here are three basics to pick from while conducting the research; quantitative, qualitative, and blended techniques. The researcher may also use a quantitative study approach to check hypotheses and make predictions by means of using measured amounts and, in the long run, describe an event via the use of figures as defined in Kowalczyk (2016). This approach enables the researcher to apply for numbers in statistical tests to make certain that the effects have a statistical dating and uses numbers to explain their findings.

The researcher used a qualitative research method to describe a topic's type and satisfaction whilst deciphering and attempting to understand an occasion. This approach allows the researcher to use texts to explain their findings. Via this study's technique, the audience is given a mental picture of what the researcher sees, making it difficult to quantify effects with statistical methods. Therefore, a researcher may additionally pick a blended method in which a combination of quantitative and qualitative techniques describes an event. With mixed strategies, biases often associated with one method (quantitative or qualitative) are notions to cancel out (Creswell, 2003). Mixed strategies research can help get deep know-how of any research. However, because 
the combined studies approach calls for extra effort and time than either qualitative or quantitative methods, this method must be used only for that studies in which profound know-how of the phenomenon is of incredible importance to the researcher.

Along with the quasi-experimental layout, a mixed-method approach became adopted to look at as a way of exploiting the strengths and minimizing the weaknesses of both quantitative and qualitative procedures. Gillham (2000) makes a sturdy case for the usage of combined strategies, arguing that making use of just one method in studies is rarely satisfactory. Based on this advice, this examination includes a method in research that is hardly ever adequate. Based on this recommendation, this examination includes an exploratory mixed-method layout in which quantitative and qualitative research facts and techniques serve to assist and validate every other.

\subsection{Quantitative Data Collection Instruments}

The researchers adopted the quantitative studies methods that commonly involve the systematic collection of information about a phenomenon, standardized measures, and statistical evaluation. In this research, quantitative information amassing information from responses to preset questions, accumulating numeric records, and collecting information from a huge quantity of individuals (Creswell, 2005). Subsequently, studies devices had been employed, pre-and post-reading comprehension, and an analyzing approach used a questionnaire to gain information on how analyzing strategies enable L2 comprehension efficaciously. According to Hammarberg et al. (2016), quantitative research techniques are suitable while factual statistics are required to answer the research questions; when fashionable or chance statistics are sought on opinions, attitudes, perspectives, ideas, or preferences; when variables can be isolated and described; whilst variables may be related to form hypotheses earlier than facts series; and while the query or hassle is thought, clear and unambiguous.

\subsubsection{Reading Comprehension Test}

In experimental studies, testing for gathering numerical research data is an essential task. The results obtained from pre-and post-test can be widely employed for the various purposes of analysis. Davies (1990) defined the roles of language testing as 1) operationalization of theoretical constructs; 2 ) a mean of establishing goals and standards for teaching courses and syllabuses; 3 ) methodology for carrying out empirical research in applied linguistics.

On this look at, a pretest of reading comprehension turned into used to study the levels of users to determine preexisting subject information in science challenge and put up-check to study the stages of reading proficiency of the collaborating college students in technology that allows you to examine the efficacy of the two methods to analyzing education. Pre-test and posttest instructional phases measure the participating students' reading abilities in Science in English. The researcher had developed the pretest and post-test based on the Science course outline in Thai syllabus. The pretest and post-test have a time limit of one hour and were constructed according to the secondary national curriculum's principles 2010. It contained 30 questions, multiple-choice-type tests with our alternatives covering biology, chemistry and physics.

\subsubsection{Qualitative Data Collection Instruments}

Qualitative research techniques consist of the systematic selection, arrangement, clarification, and analysis of written, verbal or visible data (which might normally be no longer able to counting or measuring) to cope with questions on perception, importance, and angle, most usually from the point of view of the researcher. Common guidelines for assessing qualitative research are available (Kitto et al., 2008); consequently, the qualitative techniques may be evaluated in the outcome (DixonWoods et al., 2006; young et al., 2014). In step with Hammarberg et.al, (2016), qualitative research strategies consist of 1.- smallorganization discussions, for investigating beliefs, attitudes and ideas of normative behavior; 2.- semi-based interviews, to seek views on a centred subject matter or, with key informants, for background statistics or an institutional attitude; 3.- in-depth interviews, to apprehend a circumstance, enjoy, or occasion from a personal perspective; and 4.- analysis of texts and information, which includes authentic papers, newspaper posts, blogs or diaries, for the cause of mastering approximately allotted or private records. Therefore, in this study, the software of semi-established interview techniques will permit the researcher to evaluate the participant's views on a centred subject matter or, with key informants on analyzing strategies, science modules, and teaching guides, and determine whether the techniques work with research questions.

\subsection{The Research Design}

This research's most important motive is to find an excellent approach to coaching clinical analyzing comprehension of clinical capability college students. The researcher is interested in measuring strategies guidance on scientific reading comprehension. Hence, the researcher needs to test upon the experimental sorts' vital elements to modify and manipulate conditions that affected the occasions inside which they may be involved. In different phrases, a test includes creating a trade in the cost of one variable (i.e., the independents variable) and gazing at the impact of the exchange on some other variable (i.e. the based variable) (Cohen, Manion, \& Morrison, 2000). In line with McDonough and McDonough (1997), studies of the experimental type 
desire cautious instruction for research tools like a collection of questions, a sure set of variables, specific tasks which can be measured, an acceptable range of contributors to permit statistical inferences to be made, manage and counterbalance to remove rival interpretations of data and a mean of making sure the relevance of the effects to the questions. Therefore, there is a hazard for the prevailing researcher to govern the training context; it is suitable to fashion a test to research analyzing techniques preparation through clinical analyzing modules hired through technology students within the EFL studying process.

\subsubsection{Reliability as Stability}

These studies investigated the issues and perceived wishes in teaching and studying science in English of EFL students employing a pre-take a look at, post-take a look at, questionnaire, and interview questions due to the method to acquire positive facts. To establish the questionnaires' reliability and the interview comments, the researcher decided on three qualified ESP teachers to be the raters to gauge and propose all the questions for pre-take a look at, put up-test, questionnaire, and interview questions. A reliable device for research will yield comparable information from comparable respondents over time, thanks to stability. The staleness can be a measure of consistency over time and similar samples to guarantee the consequences' confidentiality.

Correlation coefficients will be calculated for the reliability of pre-and post-test, the usage of formulae that are convenient to have in books on data, and take a look at construction. Additionally, to balance over the years, reliability as stability may even be high-quality capacity over an equal sample. As an example, we would expect that if we had been to administer a check or a questionnaire simultaneously to 2 companies of scholars who were very carefully matched on significant characteristics (e.g. age, gender, capability, etc. - anything characteristics are deemed to very own a significant bearing, at the responses), then similar outcomes (on a take a look at) or responses (to a questionnaire) would be obtained. The correlation coefficient on this form of taking a look at/re-test technique can be calculated both for the total-textual content (e.g. by way of using the Pearson statistic or at-take a look at) or for sections of the questionnaire (e.g. by means of the usage of the Pearson statistic or Spaceman as appropriate or a T-check). The correlation coefficient's statistical significance is frequently located and perhaps 0.05 or better if reliability is assured. This type of reliability over a pattern is specifically beneficial in pilot tests.

\subsubsection{Teacher and Raters}

The qualified ESP teacher selected in this study has been teaching Science in English at secondary school for more than ten years and currently teaches science in English to two high school students, aged 13 to 14 years. The teacher has got Master degree in Applied Linguistics and a Master's degree in Science (Information Technology), and has a combined experience of teaching English and Science for twenty years. Three raters selected in this study were experienced teachers in secondary school English and Science subjects, and have experience in their fields for more than 10 years. They were assigned to check, evaluate, and recommend improving the pre-test, post-test, and questionnaires during materials preparation. Both teacher and raters' credentials are outlined in Table 3.1.

Table 1: A Demography of the Teacher and Rater Participants

\begin{tabular}{|c|c|c|c|c|c|c|}
\hline Pseudonym & $\begin{array}{l}\text { Years } \\
\text { experience }\end{array}$ & of & MA qualification & $\begin{array}{l}\text { Research } \\
\text { conducted }\end{array}$ & activities & Academic position \\
\hline
\end{tabular}

Teacher

$\begin{array}{llll}\text { 1. Eng. Sci. T } & 20 & \text { Applied Linguistic } & \text { Teaching Science in English and Science } \\ & \text { Information Technology } & \text { English } & \text { Teacher }\end{array}$

Raters

\begin{tabular}{|c|c|c|c|c|}
\hline 1. Language $R$ & 15 & Applied Linguistics & Teaching English & English teacher \\
\hline 2. Science R & 10 & Science & Teaching Science & Science teacher \\
\hline
\end{tabular}




\subsubsection{Design the Eight Scientific Reading Modules}

The layout of medical modules for reading strategy preparation consists of each chapter's type of approach. First, the researcher informed the students that they were going to use any of the techniques for the duration of reading comprehension schooling classes. The teaching material was designed according to 3 basic reading instructions as follows:

\section{Pre-reading activity}

Pre-studying obligations tend to be characteristic as 'a bridge of types between a reader's information base and the textual content' (Tierney and Cunningham, 1991, p.610). Pre- reading pursuits to get college students interest and raise their hobby to the reading text. This will be accomplished with the aid of introducing the name, subtitle, textual content organization, previewing vocabulary, searching at photos, maps, diagrams, or graphs, and their captions. Analyzing comprehension questions in advance can also help to cognizance interest in finding those statistics simultaneously as reading.

\section{While-reading activity}

The while-studying interest changed into checking comprehension of what is being examined. While reading the textual content, college students had to test whether they could realize the whole textual content and whether they could reap their heritage information that they discovered inside the Thai model they wanted from the text to achieve their studying functions. Before reading the primary analyzing text, college students have been supplied with a rereading interest. The students had been asked to price the essential matters to them in an associate. In this interest, the researcher assigned the students to paintings for my part, after which requested them to talk about their solutions in pairs. After that, the researcher requested some college students to explain why they solve the questions within the same or special from others. Students had been assigned to experiment with the text to test which of the statements supplied have been made via which correspondent. On this activity, college students have been given the possibility to exercise using a scanning approach at a worldwide degree to finish the mission.

\section{Post-reading activity}

Post-studying sports give college students the possibility to practice studying and reiterate what they have learned in the lesson. Furthermore, they give students opportunities to monitor or examine their achievements. Within the put-up-reading interest, the students were given opportunities to test their comprehension by answering questions, increasing vocabulary, and giving opinions. The three steps of analyzing practice had been designed to inspire college students to apply studying strategies more appropriately and correctly. The steps were explicitly explained to the students and utilized to organize the thirty-nine closedreaction questionnaire, which was also divided according to the 3 classes earlier than reading the text while analyzing and after reading the text.

\section{Research Findings}

Reading Strategies used by Experimental Group comprises 20 statements each followed by 5-point Likert scale through which students are supposed to report how often they use each strategy. The twenty (20) reading strategies statements were classified into willpower, Social Affective, memory strategies, Cognitive and Metacognitive techniques. The researcher adopted the Revised Metacognitive Awareness of Reading Strategies Inventory, MARSI-R by Mokhtari \& Sheorey (2002), a standardized check of analyzing techniques utilized in academic studying to measure the collaborating topics' employment level of the reading techniques before and after pre-and publish-assessments remedy. The main motive of utilizing MARSI-R format questionnaire as a put up-take a look at were to explore whether the experimental organization students have performed any development as the end result of the studying strategies preparation they had been exposed to at some stage in the training program compared to the controlled group.

Overall, the experimental organization submit-take a look at outcomes of the MARSI-R questionnaire confirmed a multiplied tendency in the usage of various studying strategies. Statistics analysis discovered that the experimental institution students reflected higher strategy employment stage and achieved better suggest values of their put up-test results in comparison to their pre-take a look at outcomes which can be attributed to the reading techniques coaching, they acquired over eight clinical modules as shown in Table 5.9 below. 


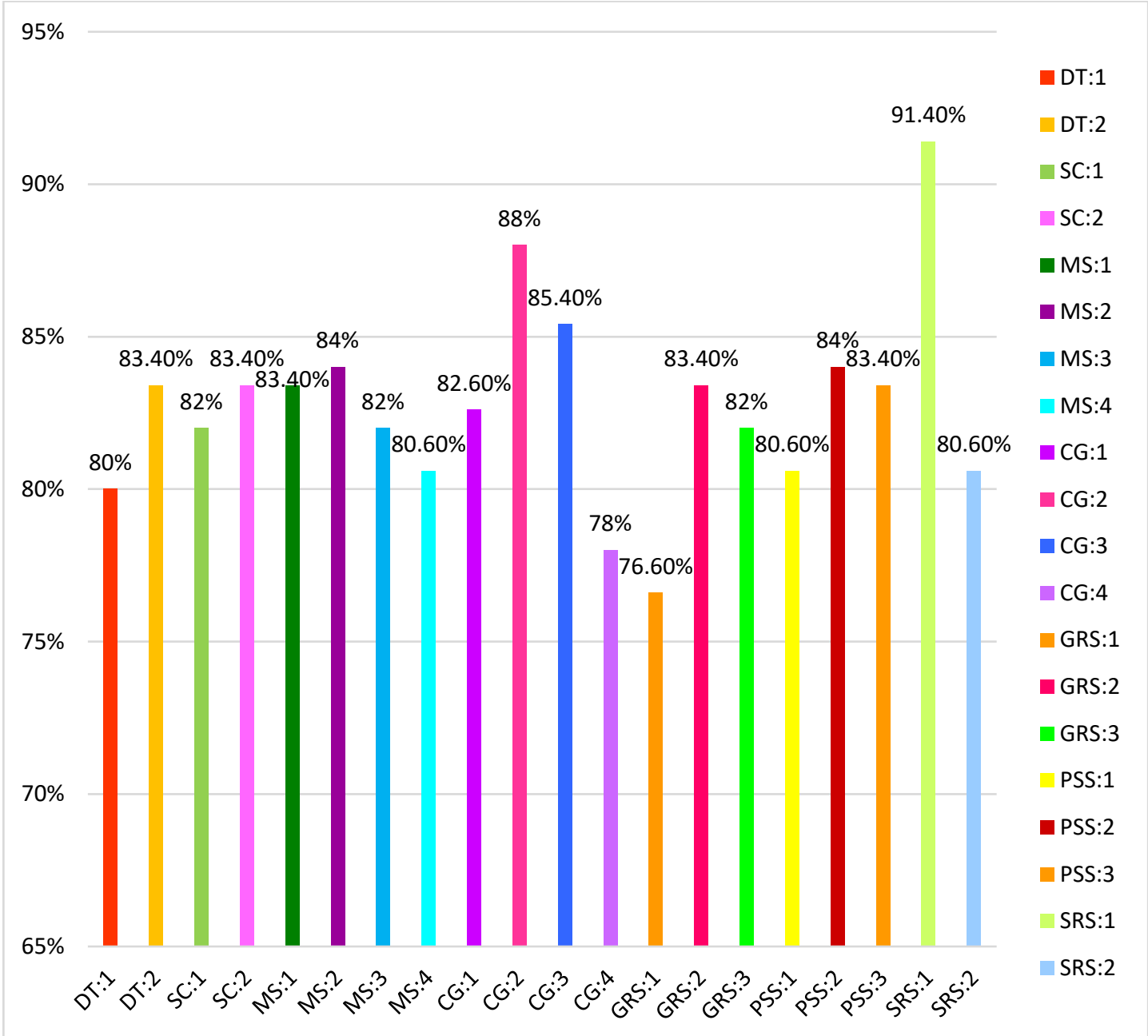

Figure 1: Reading Strategies used by Experimental Group

Table 2: Reading Strategies used by Experimental Group

\begin{tabular}{|c|c|c|c|c|}
\hline Category & Strategies & Mean & S. D & Level of Use \\
\hline DT:1 & $\begin{array}{l}\text { Guess the meanings of words from textual } \\
\text { context. }\end{array}$ & $\begin{array}{l}4.00 \\
80 \%\end{array}$ & 0.743 & $\begin{array}{l}\text { Frequently / } \\
\text { Often }\end{array}$ \\
\hline DT:2 & Look up a word in English-Thai dictionary. & $\begin{array}{l}4.17 \\
83.4 \%\end{array}$ & 0.791 & $\begin{array}{l}\text { Frequently / } \\
\text { Often }\end{array}$ \\
\hline SC:1 & $\begin{array}{l}\text { Ask the teacher to translate the meaning of } \\
\text { a word that you do not understand or give } \\
\text { an example. }\end{array}$ & $\begin{array}{l}4.10 \\
82 \%\end{array}$ & 0.803 & $\begin{array}{l}\text { Frequently / } \\
\text { Often }\end{array}$ \\
\hline SC:2 & Ask classmates for word meanings. & $\begin{array}{l}4.17 \\
83.4 \%\end{array}$ & 0.747 & $\begin{array}{l}\text { Frequently / } \\
\text { Often }\end{array}$ \\
\hline MS: 1 & Connect the word with your experiences. & 4.17 & 0.699 & Frequently / \\
\hline
\end{tabular}




\begin{tabular}{|c|c|c|c|c|}
\hline & & $83.4 \%$ & & Often \\
\hline MS:2 & $\begin{array}{l}\text { Make a list of vocabulary arranged by topic } \\
\text { or group in alphabetical for reviewing. }\end{array}$ & $\begin{array}{l}4.20 \\
84 \%\end{array}$ & 0.805 & $\begin{array}{l}\text { Frequently } \\
\text { Often }\end{array}$ \\
\hline MS:3 & $\begin{array}{l}\text { Try to use the new word at once after } \\
\text { learning. }\end{array}$ & $\begin{array}{l}4.10 \\
82 \%\end{array}$ & 0.885 & $\begin{array}{l}\text { Frequently } \\
\text { Often }\end{array}$ \\
\hline MS:4 & $\begin{array}{l}\text { Reading aloud to help me understand what } \\
\text { I'm reading }\end{array}$ & $\begin{array}{l}4.03 \\
80.6 \%\end{array}$ & 1.033 & $\begin{array}{l}\text { Frequently } \\
\text { Often }\end{array}$ \\
\hline CG:1 & Learn the word through written repetition. & $\begin{array}{l}4.13 \\
82.6 \%\end{array}$ & 1.008 & $\begin{array}{l}\text { Frequently } \\
\text { Often }\end{array}$ \\
\hline CG:2 & $\begin{array}{l}\text { Take notes of the newly-learned words in } \\
\text { class. }\end{array}$ & $\begin{array}{l}4.40 \\
88 \%\end{array}$ & 0.675 & $\begin{array}{l}\text { Frequently } \\
\text { Often }\end{array}$ \\
\hline CG:3 & Use the vocabulary section in your textbook. & $\begin{array}{l}4.27 \\
85.4 \%\end{array}$ & 0.691 & $\begin{array}{l}\text { Frequently } \\
\text { Often }\end{array}$ \\
\hline CG:4 & $\begin{array}{l}\text { Skimming used to search main ideas and } \\
\text { scanning used to find specific details. }\end{array}$ & $\begin{array}{l}3.90 \\
78 \%\end{array}$ & 0.845 & Sometimes \\
\hline GRS:1 & Having a purpose in mind when reading & $\begin{array}{l}3.83 \\
76.6 \%\end{array}$ & 0.648 & Sometimes \\
\hline GRS:2 & $\begin{array}{l}\text { Previewing text to see what it is about } \\
\text { before reading }\end{array}$ & $\begin{array}{l}4.17 \\
83.4 \%\end{array}$ & 0.699 & $\begin{array}{l}\text { Frequently } \\
\text { Often }\end{array}$ \\
\hline GRS:3 & $\begin{array}{l}\text { Using typographical aids like bold face and } \\
\text { italics to pick out key information }\end{array}$ & $\begin{array}{l}4.10 \\
82 \%\end{array}$ & 0.803 & $\begin{array}{l}\text { Frequently } \\
\text { Often }\end{array}$ \\
\hline PSS:1 & $\begin{array}{l}\text { Stopping from time to time to think about } \\
\text { what I'm reading } 4\end{array}$ & $\begin{array}{l}4.03 \\
80.6 \%\end{array}$ & 0.765 & $\begin{array}{l}\text { Frequently } \\
\text { Often }\end{array}$ \\
\hline PSS:2 & $\begin{array}{l}\text { Re-reading to make sure I understand what } \\
\text { I'm reading }\end{array}$ & $\begin{array}{l}4.20 \\
84 \%\end{array}$ & 0.714 & $\begin{array}{l}\text { Frequently } \\
\text { Often }\end{array}$ \\
\hline PSS:3 & $\begin{array}{l}\text { Practice by doing vocabulary exercises (e.g. } \\
\text { filling words in the gaps.) }\end{array}$ & $\begin{array}{l}4.17 \\
83.4 \%\end{array}$ & 0.874 & $\begin{array}{l}\text { Frequently } \\
\text { Often }\end{array}$ \\
\hline SRS:1 & $\begin{array}{l}\text { Underlining or circling important } \\
\text { information in text }\end{array}$ & $\begin{array}{l}4.57 \\
91.4 \%\end{array}$ & 0.679 & $\begin{array}{l}\text { Frequently } \\
\text { Often }\end{array}$ \\
\hline SRS:2 & $\begin{array}{l}\text { Using reference materials such as } \\
\text { dictionaries or Thai textbook to support my } \\
\text { reading }\end{array}$ & $\begin{array}{l}4.03 \\
80.6 \%\end{array}$ & 0.850 & $\begin{array}{l}\text { Frequently } \\
\text { Often }\end{array}$ \\
\hline
\end{tabular}


Willpower techniques have been measured using two one-of-a-kind units; guess the meanings of words from the textual context, and look up a word in the English-Thai dictionary. As shown in Table 5.1, the result of figuring out strategies indicated that participants frequently/often bet the meanings of words from the textual context that they did no longer apprehend $(M=4.00, S D=0.743)$ and further appeared up for unknown words in an English - Thai dictionary $(M=4.17, S D=0.791)$.

Motivation-to-study is a factor proven to positively narrate reading comprehension (Guthrie, Coddington, \& Wigfield, 2009; Solheim, 2011; Wigfield, et al., 2008). On this observation, effective social strategies were measured using two one-of-a-kind contraptions; Ask the teacher to translate the meaning of a phrase that you do not understand or give an example, and Ask classmates for phrase meanings. The result is on Table 5.9 revealed that the participants asked the meaning of unknown words from classmates $(M=0.17, S D=0.747)$ and inquiring for translation of meaning via instance from the teacher once they did not understand $(M=4.10, S D=0.803)$ and to ensure that they correctly understand the factors of the texts so that they can interpret extra simply and thoroughly.

The oblique relationship between motivation (asking classmates and teacher) and reading comprehension is that studying comprehension increases when a reader has an innate preference to examine. This point is subsidized through pupils of selfdetermination who contend that internally-stimulated students experience extra educational fulfillment and admire college extra (Reeve, 2002). With a view to measure the relevance of operating reminiscence to reading in well-known and studying knowhow particularly, a plethora of studies have been carried out (Alloway, Gathercole, Adams, \& Willis, 2005; Ericsson, \& Kintsch, 1995; Jeffries, \& Everatt, 2004; McCallum, Bell, wooden, beneath, Choate, \& McCane, 2006).

Working memory is the ability to shop and manner information simultaneously (Swanson \& Ashbaker, 2000), and became directly related to studying comprehension. In this study, running reminiscence become measured the use of 4 exclusive gadgets; connect the phrase with your experiences $(M=4.17, S D=0.699)$, Make a listing of vocabulary organized by way of subject matter or organization in alphabetical for reviewing $(M=4.20, S D=0.805)$, try to use the brand-new word at once after learning $(M=4.10, S D=0.885)$, studying aloud to assist me to apprehend what I am reading $(M=4.03, S D=1.033)$.

One conclusion drawn from these outcomes is that once vocabulary and phrase recognition sports were endorsed, their reminiscence is more advantageous. Similar findings had been mentioned by Christopher et al. (2012), who indicated that working reminiscence became a predictor of both phrase reading and studying comprehension, and running reminiscence is shared among both variables. They observed that studying understanding will increase with word studying, explaining development in operating memory. As an immediate result of improved language abilities (word analyzing and knowledge), they postulated that running memory might enhance. The existing studies, wherein running reminiscence became especially connected to each language mastering and phrase reputation, confirm this interpretation.

For cognitive techniques, the locating proven that most members take notes of the newly-found out phrases in class ( $M=4.40$, $S D=0.675)$, and use the vocabulary phase of their textbook $(M=4.27, S D=0.691)$. Moreover, additionally, they study the phrase via written repetition $(M=4.13, S D=1.008)$, however from time to time, use a skimming strategy to look for predominant thoughts and scanning to find precise info $(M=3.90, S D=0.845)$. The end result of this observation guide to the countrywide reading Panel file (NICHD, 2000) findings that comprehension may be progressed by way of teaching students to apply specific cognitive techniques or to purpose strategically after they stumble upon barriers to knowing what they are analyzing (p. 14). That is covered with the current studies intervention or analyzing strategies coaching the use of CALLA method in this experiment. This resulted in them not trying to exert themselves extra in making use of effective reading techniques, however, additionally to conquer the present reading issues.

For metacognitive techniques, MARSI-R includes 3 classes of techniques, worldwide analyzing techniques (GRS), hassle-fixing strategies (PSS), and support analyzing strategies (SRS). Worldwide reading techniques (GRS) are those deliberate, deliberately designed approaches by which college students' music or manage their studying, consisting of retaining a target in thoughts, showcasing the text in phrases of its period and enterprise, or the use of syntactical aids and tables and figures. In this have a look at, GRS has measured the use of 3 extraordinary devices; Having a purpose in thoughts while analyzing $(M=3.83, S D=0.648)$, Previewing textual content to look what it is miles about before studying ( $M=4.17, S D=0.699)$, the usage of typographical aids like boldface and italics to choose out key facts $(M=4.10, S D=0.803)$

Problem-solving strategies (PSS) are the movements and methods that readers use while working without delaying the textual content. These are localized, focused techniques used when troubles expand in textual knowledge facts; examples include adjusting one's reading speed whilst the material turns into complex or easy, guessing the meaning of unknown phrases, and restudying the text to enhance comprehension. On this look at, PSS had been measured the usage of three one-of-a-kind gadgets; 
stopping from time to reflect consideration on what I am reading $(M=4.03, S D=0.765)$, Re-reading to ensure I apprehend what I am reading $(M=4.20, S D=0.714)$, practice with the aid of doing vocabulary sporting activities $(M=4.17, S D=0.874)$. Guide analyzing techniques (SRS) are fundamental support mechanisms meant to help the reader comprehend the text, including using a dictionary, taking notes, underlining, or highlighting textual records. SRS had been measured using distinctive gadgets; Underlining or circling vital facts in textual content $(M=4.57, S D=0.679)$, and using reference materials inclusive of dictionaries or Thai textbook to aid my studying $(M=4.03, S D=0.850)$.

It is far exciting that 5 of the reading techniques frequently used by maximum members point closer to constructing a vocabulary repository. The strategies in this class beginning with Underlining or Circling important data in text $(X=4.57$, $S D=0.679)$, accompanied through the Take notes of the newly-discovered phrases in class $(X=4.40, S D=0.675)$, Use the vocabulary phase to your textbook $(X=4.27, S D=0.691)$, Make a listing of vocabulary arranged by subject matter or organization in alphabetical for reviewing $(X=4.20, S D=0.805)$, and reanalyzing to make sure I understand what I am reading $(X=4.20$, $\mathrm{SD}=0.714$ ) had been determined at the high degree of utilization.

Consequently, the null hypothesis;

The researcher examined the family's developmental members among analyzing strategies and reading comprehension in clinical modules of EFL grade 7 college students in Thailand. Opinions have consistently proven outcomes of interventions to enhance the know-how and use of analyzing techniques on intervention associated with reading comprehension. The results showed that there had been a relationship between studying comprehension and analyzing techniques which are depending on numerous cognitive, metacognitive expertise in technological know-how. The expertise of which means of the scientific vocabulary inside the text is essential to recognize the text, the storage of records from the text, and English capability with history expertise. These processes contain working reminiscence and maximum contributors to build a vocabulary repository. For the metacognitive procedures, the reader used throughout text comprehension, which metacognitive issues expertise approximately the law of cognitive methods in studying sports (Brown, 1978; Flavell, 1979). The best scientific textual content emerges from the text to background expertise. Employing proper scientific Modules in English, using right reading strategies and guided analyzing techniques training enhances the students to benefit from higher reading comprehension in clinical modules.

The findings revealed that the training application that integrated with dedication techniques, social techniques, reminiscence strategies metacognitive, cognitive strategies, and support studying strategies with the 8 medical modules could enhance scholar analyzing comprehension overall performance. Quantitative facts and qualitative information studies found that metacognitive studying techniques are powerful studying mechanisms that may undoubtedly in fluent students analyse clinical modules' comprehension. This display extra frequently uses of skimming used to go looking predominant thoughts, scanning used to discover specific information, underlining or circling essential statistics in text, and using reference substances which includes dictionaries or Thai textbook to guide their reading. Building students' awareness and crucial reading strategies follow via used more frequently and the teacher confirmed them how to observe every one of them while studying is greater pretty achievement of enhancing reading ability that the students may want to gain. The greater common use of analyzing techniques, the higher achievement in scientific studying ability the scholars could attain. The analyzing strategies make them intimated courting among themselves and the analyzing text and regulating a person's progress accordingly.

\section{Discussion}

This study aimed to train EFL Thai students on effective reading strategies that would elevate their reading quality and become successful readers in the future and attempt to improve EFL Thai students reading comprehension equipped by substantially reading scientific modules that could assist them in accomplishing the objectives. The aims can help EFL students overcome the existing reading problems and attempt to exert themselves more in utilizing effective reading strategies.

The locating also discovered that the five analyzing techniques that they substantially extra frequently used to assess the analyzing medical modules made it less challenging to learn the new technical phrases and expertise; they may sense the close relationship among themselves and analyse textual content. The studying strategies capabilities were influential on the students' development in studying comprehension. The researcher asks the query approximately the remarks or tips that they can give to improve the 8 medical modules. All the respondents agreed that the 8 clinical modules provided an amazing learning material that allows them to develop their studying.

The findings of the existing take a look at having implications for EFL clinical material layout, decided on and supplementation, as well as educational consciousness of technology path, define in Thai syllabus for science scholar grade 7 elegance. As cited by means of Verdugo (2007), textbooks writers must produce studying textbooks in keeping with reading functions together with language cognizance and analyzing for which means. The academic cloth design decided on this look at the used Backward 
layout approach, which focuses on studying outcomes, queries, and tasks that will offer evidence of learning. Through Backward layout, concerned with curriculum layout and academic layout facilitated studying for technology. Moreover, the educator can address the scholar's need to research, the facts amassed, and the results and ensure the scholars could benefit from mastering. This study's clinical coursebook consists of biology, physics, and chemistry and analyzing techniques training. It is prescribed in the main narrative in technological know-how nature. It also covered reading strategies and observed the conventional comprehension pre-check and submit-check.

They also acknowledge that reading strategies instruction introduces them to effective reading strategies. They realized that it was difficult at the initial stage to understand the scientific vocabularies and link them to the whole passage, but through guidance and indirect exposure to reading strategies, they gain confidence, motivation, and improve their reading pace after being exposed several times. They encourage teachers to use the scientific modules in English class, expose students to reading strategies, and assist them in reading comprehension. Finally, the lower participants preferred the materials itself because it was designed to suit with Thai version so they were good and beneficial as they can convey my knowledge from this class to answer the question in Thai class.

Moreover, the opposite most techniques that affected the study support studying strategies that learners pick to take when they encountered the difficulty a part of medical reading comprehension is social techniques. The participants tended to behaviour a complete preview to clarify the goal, count on studying responsibilities, and pick out techniques for handing them by means of the assisting of social techniques. Social strategies contain cations. That newcomers pick out to take while interacting with different beginners to accomplish the common goal of gaining knowledge of tasks or interacting with local speakers to clarify social roles and relationships (Cohen, 1998; O'Malley \&Chamot, 1990). The social techniques diagnosed on this look involved the sports the individuals carry out while interacting with some other man or woman to assist analyzing or co-working with friends to acquire a commonplace purpose in analyzing. Furthermore, the contributors stated that they reduce anxiety using social techniques to experience performing the studying undertaking.

Thai EFL students experience various challenges that boosted their reading comprehension performance. In this study, the researcher proposed the training program with $\mathbf{4 0}$ hours per semester that hopefully covers all reading strategies to facilitate their comprehension and match the learner's interests. The training program, which included modifications of the current science curriculum in Thailand, was based on CALLA instructional model as the modules of delivering the reading materials. It is interesting to note that there existed significantly solid and positive correlations between reading strategies and the eight scientific modules under all categories of reading strategies. It was further found that the participants' overall use of reading strategies and English reading proficiency were positively correlated. This shows that the modules' task diversity could develop learners' positive attitudes and motivation towards reading scientific texts.

\section{Conclusion}

This examination's purpose was to raise students' focus on analyzing scientific studying modules and equipping them with the processing strategies that would allow them to become greater strategic readers. It appeared that the experimental group students have been capable of switch L2 based studying techniques that they had discovered in magnificence to clinical reading comprehension contents. The successful effects finished using the experimental group students in medical content in English shape pre-and put up-take a look at supported the research's essential hypothesis. The improvement of the experimental institution performed of their put-up analyzing comprehension test results shows that incorporating metacognitive, cognitive, dedication, social, and memory techniques correlates positively with studying comprehension success. The studies usually endeavored to discover the effectiveness of five variables more likely to adjust to studying undertaking. Consequently, these techniques might affect students' reading comprehension overall performance correctly, much less effort and time than before.

Quantitative data findings revealed that students' metacognitive, cognitive studying techniques employment were elevated, and therefore analyzing overall comprehension performance was progressed. College students of the training program shared their reviews within the semi-based interview to further improve their clinical studying comprehension extra without problems. A maximum of the scholars (80 \%) responded from semi-established interviews that incorporating metacognitive, cognitive, willpower, social, and memory techniques within the education elegance convey advantages to studying comprehension and mastering. Exploring the students' reactions confirmed that in the education application, studying strategies helped them learn new talents and changed their attitude towards science in English elegance, which they can apprehend via analyzing activities in elegance.

\subsection{Recommendations for Further Research}


To demonstrate the truth that taking determination techniques, social techniques, reminiscence strategies, cognitive techniques, metacognitive techniques, and support studying strategies correlate positively with the 8 studying clinical modules into attention, the schooling application changed into based totally on a few selected analyzing strategies, the researcher also summarized some guidelines which are hoped to offer useful statistics to future efforts within the field of improving teaching science in English of EFL. As a result, teachers must adapt cognitive and metacognitive techniques to analyse elegance. Teachers as well as college students especially in the EFL context should be trained on employing these strategies in EFL classroom. To construct lifelong studying and self-sustaining newbies, teachers should encourage college students to adapt and analyze techniques while studying to permit them to more effective questioning, learning, and reflecting on their reading comprehension to benefit the new knowledge. For analyzing development, it would be thrilling to behavior a longitudinal examination to look at the spontaneous reading behavior of young newbies.

\subsection{Further Study}

Furthermore, it is suggested that reading strategies training program be introduced to Science EFL teachers to raise awareness of the effective use of reading strategies. Further study is commended for investigating the use of reading strategies through alternative assessment such as science classroom observation, visual aids for fruitful and precise research findings. Teachers and students, especially in the EFL context, should be taught to employ reading strategies such as determination strategies, social strategies, memory strategies, cognitive strategies, and metacognitive strategies in EFL classrooms. To build lifelong learning and autonomous learners, teachers should motivate students to adapt and adopt reading strategies while reading to enable them to be more effective in thinking, learning and reflecting on their reading comprehension to gain new knowledge.

\section{Acknowledgements}

I wish to thank Assoc. Prof. Dr. Jafre Bin Zainol Abidin for his diligent supervision, Miss Jarinya Srimanee, for her dedicated assistance and support. My thanks also go to the anonymous reviewers for their helpful comments on the article and the participants in this study.

\section{References}

[1] Alloway, T. P., Gathercole, S. E., Adams, A. M., Willis, C., Eaglen, R., \& Lamont, E. (2005). Working memory and phonological awareness as predictors of progress towards early learning goals at school entry. British Journal of Developmental Psychology, 23(3), 417-426.

[2] Bernhardt, E. B. (2005). Challenges to reading research from a multilingual world. Reading

a. Research Quarterly, 38(1), 112-117.

[3] Cohen, L., Dehaene, S., Vinckier, F., Jobert, A., \&Montavont, A. (2008). Reading normal and degraded words: contribution of the dorsal and ventral visual pathways. Neuroimage, 40(1), 353-366.

[4] Creswell, J. W. 2003. Qualitative, quantitative and mixed methods approaches. Thousand Oaks, CA: Sage Publications.

[5] Creswell, J. D. (2005). Mixed methods research designs in counseling psychology. Journal of Counseling Psychology, 52(2), 224235. https://doi.org/10.1037/0022-0167.52.2.224

[6] Darasawang, P. (2007). English language teaching and education in Thailand: A decade of change (pp. 187-204). UK: Cambridge Scholars Publishing.

[7] Darasawang, P., \& Watson Todd, R. (2012). The effect of policy on English language teaching at secondary schools in Thailand. In E. L., Low, \& A. Hashim. (Eds.). (2012). English in Southeast Asia: Features, policy and language in use (p. 42). Amsterdam, Netherlands: John Benjamins Publishing.

[8] Davies, A. (1990). Principles of language testing. New Jersey: Wiley-Blackwell.

[9] Dixon-Woods, M., Bonas, S., Booth, A., Jones, D. R., Miller, T., Sutton, A. J., ... \& Young, B. (2006). How can systematic reviews incorporate qualitative research? A critical perspective. Qualitative Research, 6(1), 27-44.

[10] Grabe, W. (2004). Research on teaching reading. Annual Review of Applied Linguistics, 24, 44-69. doi: doi:10.1017/\$0267190504000030

[11] Gillham, B. (2000). Case study research methods. London: Bloomsbury Publishing.

[12] Guthrie, J. T., Coddington, C. S., \&Wigfield, A. (2009). Profiles of reading motivation among African American and Caucasian students. Journal of Literacy Research, 41(3), 317-353.

[13] Hammarberg, K., Kirkman, M., \& de Lacey, S. (2016). Qualitative research methods: when to use them and how to judge them. Human reproduction, 31(3), 498-501.

[14] Hood, S., Solomon, N., \& Burns, A. (1996). Focus on reading. Retrieved from ERIC database (ED411713).

[15] Kitjaroonchai, N. (2012). Motivation toward English language learning of students in secondary and high schools in education service area office 4, Saraburi Province, Thailand. International Journal of Language and Linguistics, 1(1), 22-33.

[16] Kitto, S. C., Chesters, J., \&Grbich, C. (2008). Quality in qualitative research. Medical Journal of Australia, 188(4), $243-246$.

[17] Koda, K. (2007). Reading and language learning: Crosslinguistic constraints on second language reading development. Language Learning, 57(1), 1-44

[18] Kowalczyk, D. (2016). Research methodologies: Quantitative, qualitative, and mixed methods [video file]. Retrieved from http://study.com/academy /lesson/researchmethodologies-quantitative-qualitative-mixed-method.html

[19] McDonough, J. \& McDonough, S., (1997). Research Methods for English Language Teachers. London: Arnold.

[20] Mokhtari, K., \&Sheorey, R. (2002). Measuring ESL students' awareness of reading strategies. Journal of Developmental Education, 25(3), 210.

[21] Reeve, J. (2002). Self-determination theory applied to educational settings. In E. L. Deci \& R. M. Ryan (Eds.), Handbook of self-determination research (p. 183-203). University of Rochester Press. 
[22] Solheim, O. J. (2011). The impact of reading self-efficacy and task value on reading comprehension scores in different item formats. Reading Psychology, 32(1), 1-27.

[23] Tierney, R. J., \& Cunningham, J. W. (1991). Research on teaching reading comprehension. In R. Barr, M. Kamil, P. Mosenthal, \& P. D. Pearson (Eds.), Handbook of reading research (Vol. 2, pp. 609-640). Mahwah, NJ: Lawrence Erlbaum Associates.

[24] Wigfield, A., Guthrie, J. T., Perencevich, K. C., Taboada, A., Klauda, S. L., McRae, A., \& Barbosa, P. (2008). Role of reading engagement in mediating effects of reading comprehension instruction on reading outcomes. Psychology in the Schools, 45(5), 432-445.

[25] Wiriyachitra, A. (2001). A Thai University English Scenario in the Coming Decade. ThaiTESOL, 14(1), 4-7. 